\title{
Assessment of Human Health Risk of Potential Toxic Metals in Herbal Concoction Teas Commonly Consumed in Nigeria
}

\author{
Solomon Sunday Durodola ${ }^{1,}$, Olawole Ayinuola ${ }^{1}$, Odunayo Timothy Ore ${ }^{1}$, \\ Oladotun Wasiu Makinde ${ }^{2}$ \\ ${ }^{1}$ Department of Chemistry, Obafemi Awolowo University, Ile-Ife, Nigeria \\ ${ }^{2}$ Centre for Energy and Research Development, Obafemi Awolowo University, Ile-Ife, Nigeria
}

Email address:

solomonsun77@gmail.com (S. S. Durodola)

*Corresponding author

\section{To cite this article:}

Solomon Sunday Durodola, Olawole Ayinuola, Odunayo Timothy Ore, Oladotun Wasiu Makinde. Assessment of Human Health Risk of Potential Toxic Metals in Herbal Concoction Teas Commonly Consumed in Nigeria. World Journal of Applied Chemistry. Vol. 4, No. 3, 2019, pp. 35-41. doi: 10.11648/j.wjac.20190403.12

Received: August 31, 2019; Accepted: September 20, 2019; Published: September 30, 2019

\begin{abstract}
Concentrations of potential toxic metals $(\mathrm{Pb}, \mathrm{Cr}, \mathrm{Cu}, \mathrm{Zn}, \mathrm{Ni}, \mathrm{Co}, \mathrm{As}, \mathrm{Fe}$ and $\mathrm{Mn}$ ) were determined in herbal concoction teas commonly consumed in Nigeria using Atomic Absorption Spectrophotometry. Results revealed that Fe had the highest concentration with a mean value of $13.136 \pm 0.195 \mu \mathrm{g} / \mathrm{g}$, while As had the least mean concentration $(0.043 \pm 0.006$ $\mu \mathrm{g} / \mathrm{g}$ ). Pollution index (PI) result indicated that the teas were contaminated with $\mathrm{Cu}$ (PI value $>1$ ) while it was clear of contamination by the other investigated metals. Cluster analysis showed close inter-element relationships between the investigated metals, indicating similar chemical properties and/or genetic origin. Correlation matrix showed that positive and significant correlations existed between between $\mathrm{Zn} / \mathrm{Cr}, \mathrm{Ni} / \mathrm{Cr}, \mathrm{Co} / \mathrm{Cr}, \mathrm{Fe} / \mathrm{Cu}, \mathrm{Mn} / \mathrm{Cu}, \mathrm{Ni} / \mathrm{Zn}, \mathrm{Co} / \mathrm{Zn}, \mathrm{Co} / \mathrm{Ni}$ and $\mathrm{Mn} / \mathrm{Fe}$, indicating chemical affinity. Estimated daily intake, target hazard quotient and cancer risk showed that there was no health risk associated with the consumption of the herbal concoction teas. Relative risk indicated that the highest concern is from the levels of Co in the teas. The study concluded that consumption of the teas may not pose risk to human health at the current levels of the metals, but should be consumed moderately to prevent bioaccumulation of the metals.
\end{abstract}

Keywords: AAS, Health Risk, Herbal Concoction Teas, Pollution, Toxic Element

\section{Introduction}

Herbal concoctions are widely used for the treatment of various illnesses. They often contain highly active pharmacological components including minerals and trace metals [1]. Herbal plants represent an important class of various traditional medicine systems and, in recent years, they are increasingly used in the primary health care intervention in both developed and developing countries. According to World Health Organization (WHO) estimates, nearly $70-80 \%$ of the world population still primarily relies on nonconventional medications, mostly derived from herbal plants $[2,3]$. In addition to herbal extracts, reports have shown the presence of heavy metals in many beverages. Though some heavy metals could be beneficial, these metals possess deleterious effect when present or their levels in food and drinks exceed the tolerable limit [4]. Interestingly, both beverages and herbal extracts separately are noted as source of heavy metals and the additive effects of heavy metals from these sources could be particularly harmful to health. Studies have reported the presence of lead, cadmium, mercury, and arsenic in beverages which lead to progressing physical, muscular, and neurologically-degenerating disease conditions $[5,6]$.

In parallel with the increasing interest in the therapeutic benefits of herbal products, there has been an increasing concern over the safety and toxicity of natural herbs and formulations available on the market. There is a widespread misconception that natural herbs and plants are inherently safe; nevertheless, there has been a large volume of reports on incidences of toxicity and adverse effects linked to the use 
of herbal plants and their formulations in different parts of the world [7, 8]. In Nigeria, the herbal concoctions are formulated by soaking the herbal plants in either water or alcohol so as to obtain the plant extracts. A common practice in Nigeria is to also allow the solution to get fermented for several days before being made available to the public for consumption. It is presumed that metals will be leached from the plant leaves or barks into the choice solvent (water or alcohol) depending on the length of time the herbal plants get dissolved in the solvent of interest. These metals, being present in the solution, will then be available for consumption to the consumers.

The exposure of humans to the elevated levels of toxic metals present in herbal concoction teas might cause serious health risks to the consumers; hence, there is a need to assess the elemental composition of the herbal concoction and its associated health risk to humans.

\section{Materials and Methods}

\subsection{Sample Collection and Preparation}

The herbal concoction tea samples were bought randomly from several sellers in Osun State (Ile-Ife and Ilesa) and Oyo State (Ibadan), Nigeria. The tea samples were collected in plastic bottles and taken immediately to the laboratory for analysis. $5 \mathrm{~mL}$ each of the tea samples was digested in a 125 $\mathrm{mL}$ Teflon bomb with $3 \mathrm{~mL}$ of concentrated $\mathrm{HNO}_{3}$ and $3 \mathrm{~mL}$ $50 \% \mathrm{H}_{2} \mathrm{O}_{2}$. After digestion, the bomb was allowed to cool to room temperature for a few hours. The digested sample was poured into a $50 \mathrm{~mL}$ volumetric flask, and double-distilled water was used to rinse the Teflon bomb into the volumetric flask; the flask was filled to the mark with double-distilled water [9].

\subsection{Elemental Analysis}

The elemental analysis of the herbal concoction tea samples was performed using Atomic Absorption Spectrophotometer (AAS) Model Alpha Star 4 (ChemTech Analytical) at the Centre for Energy Research and Development (CERD), Obafemi Awolowo University, IleIfe, Nigeria. The instrument was operated in accordance with the instrument's handbook while calibration was done using a mixed calibration standard solution prepared from the pure British Drug House (BDH) Analar grade salt of each metal.

\subsection{Quality Assurance}

The accuracy of the procedure employed was assured by spiking two $5 \mathrm{~mL}$ portions of each of the herbal concoction tea samples for recovery analysis. One portion was spiked with $5 \mathrm{ml}$ of $5.0 \mu \mathrm{g} / \mathrm{g}$ standard mixtures of the heavy metal solution while the other portion was left unspiked. Both the spiked and unspiked portions were separately digested. The percentage recovery $(\%)$ of the heavy metals was determined by comparing the concentrated values of each metal from spiked and unspiked samples using the expression:

$$
\left[\mathrm{A}-\mathrm{A}^{\prime}\right] / \mathrm{B} \times 100
$$

Where $\mathrm{A}=$ Heavy metal concentration in spiked herbal concoction tea samples

$\mathrm{A}^{\prime}=$ Heavy metal concentration in unspiked herbal concoction tea samples and

$\mathrm{B}=$ the amount of heavy metal used for spiking [10].

\subsection{Data Treatment}

For the interpretation of the data, the following statistical methods were used: Descriptive statistics (mean, range, standard deviation) were performed in addition to pollution index to ascertain the contamination of the samples. Cluster analysis was carried out to determine the inter-element clustering relationship. To assess the association between the analyzed metals, correlations of the heavy metals were determined between the different matrices. Human health risk assessment such as estimated daily intake, target hazard quotient, cancer risk and relative risk were carried out to determine the health risks associated with the ingestion of the samples.

Estimated Daily Intake (EDI)

Estimated daily intake (EDI) of heavy metals via ingestion route (herbal concoction teas) was calculated using Eqn. (2)

$$
\mathrm{EDI}=\frac{\mathrm{C} \times \mathrm{IR} \times \mathrm{EF} \times \mathrm{ED}}{\mathrm{BW} \times \mathrm{AT}}
$$

Assumptions for the health risk calculations were;

a. Ingested dose is equal to the absorbed pollutant dose [11].

b. The average body weight of a Nigerian adult is assumed to be $70 \mathrm{~kg}$

Where: $\mathrm{EF}=$ exposure frequency $\left(360\right.$ days year $\left.{ }^{-1}\right)$; ED = exposure duration (70 years for adults), equivalent to the average lifetime; $\mathrm{IR}=$ ingestion rate $\left(\mathrm{kg}\right.$ person $\left.{ }^{-1} \mathrm{day}^{-1}\right)$, (0.008 $\mathrm{kg}_{\text {person }}{ }^{-1}$ day $^{-1}$ for adults); $\mathrm{C}=$ metal concentration in herbal concoction teas $\left(\mathrm{mg} \mathrm{kg}^{-1}\right)$; $\mathrm{BW}=$ average body weight ( $\mathrm{kg}),(70 \mathrm{~kg}$ for adults); $\mathrm{AT}=$ average exposure time for noncarcinogens (365 days year $\left.^{-1} \times \mathrm{ED}\right)$, total THQ in this study was treated as the arithmetic sum of the individual metal THQ values [12].

Target Hazard Quotient (THQ)

The THQ, the ratio of the exposure dose to the reference dose (RfD), represents the risk of noncarcinogenic effects. If it is less than 1, exposure level is less than the RfD. This indicates the daily exposure at this level is unlikely to cause adverse effects during a person's lifetime, and vice versa. The dose calculations were performed using standard assumptions from the integrated USEPA risk analysis [13].

The target hazard quotient (THQ) was finally calculated using Eq. (3).

$$
\mathrm{THQ}=\frac{\mathrm{EDI}}{\mathrm{RfD}}
$$

In this study, the total THQ was expressed as the arithmetic sum of the individual metal THQ values according to the method [14]: 
Total THQ $($ TTHQ $)=$ THQ $($ toxicant 1$)+$ THQ $($ toxicant 2$)+\ldots$. THQ $($ toxicant $n)$

\section{Cancer Risk (CR)}

The $\mathrm{CR}$ over a lifetime of exposure to $\mathrm{Pb}$ and $\mathrm{Ni}$ was estimated using the cancer slope factor according to Eq. 5 $[15,16]$ :

$$
\mathrm{CR}=\frac{E F \times E D \times I R \times C F \times C \times C S F}{B W \times A T} \times 10^{-3}
$$

where CSF is the cancer slope factor $(\mathrm{mg} / \mathrm{kg} /$ day), while the other parameters have been defined previously. The US Environmental Protection Agency set an acceptable lifetime carcinogenic risk of $10^{-5}$ [17].

\section{Relative Risk (RR)}

the RR of contaminants for both carcinogenic and noncarcinogenic effects are defined [18], which can be helpful to recognize the most harmful contaminants. The RR equation is as follows:

$$
\mathrm{RR}=\frac{C}{R f D}
$$

where all parameters have been previously defined [18].

\section{Results and Discussion}

\section{Results of Recovery analysis}

Table 1 shows the analytical result for calibration curve and percentage recovery for the analyzed heavy metals in the herbal concoction tea samples. The percentage recovery (\%) of the heavy metals was determined by comparing the concentrated values of each metal from spiked and unspiked samples. The recoveries of metals in spiked sample were between 83.00 $93.00 \%$. Since the mean percentage recoveries for all analyte were within an acceptable range (70\% - 110\%), this gives credence to the reliability of the results of this study.

Table 1. Analytical results for calibration curve and percentage recovery $(\%$ R) for the analyzed metals

\begin{tabular}{llll}
\hline Metal & Amount spiked $(\boldsymbol{\mu g} / \mathbf{g})$ & Amount recovered $(\boldsymbol{\mu g} / \mathbf{g})$ & \% Recovery \\
\hline $\mathrm{Pb}$ & 5.00 & 4.65 & 93.00 \\
$\mathrm{Cu}$ & 5.00 & 4.26 & 85.20 \\
$\mathrm{Zn}$ & 5.00 & 4.35 & 87.00 \\
$\mathrm{Fe}$ & 5.00 & 4.15 & 83.00 \\
\hline
\end{tabular}

\section{Elemental characterization}

The levels of the analyzed metals $(\mathrm{Pb}, \mathrm{Cr}, \mathrm{Cu}, \mathrm{Zn}, \mathrm{Ni}, \mathrm{Co}$, $\mathrm{As}, \mathrm{Fe}$ and $\mathrm{Mn}$ ) in the herbal concoction tea samples are presented in Table 2, alongside their mean, range and coefficient of variation. Variations exist among the concentration of metals determined in the tea samples. $\mathrm{Cu}$ has the highest mean concentration of $13.136 \mu \mathrm{g} / \mathrm{g}$ while As has the lowest mean concentration of $0.043 \mu \mathrm{g} / \mathrm{g}$ in the tea samples. Iron is an essential element required for proper body functioning. Arsenic, on the other hand, is a toxic element that is not needed by the human body. Generally, the level of the analyzed metals in the herbal concoction teas is of the order: $\mathrm{Cu}>\mathrm{Fe}>\mathrm{Zn}>\mathrm{Mn}>\mathrm{Cr}>\mathrm{Co}>\mathrm{Ni}>\mathrm{Pb}>$ As. The concentrations of the metals are generally lower than the WHO permissible limits except for $\mathrm{Cu}$, which is higher than the permissible limit.

\begin{tabular}{|c|c|c|c|c|c|c|c|c|}
\hline $\begin{array}{l}\text { Element } \\
(\mu \mathrm{g} / \mathrm{g})\end{array}$ & SP1 & SP2 & SP3 & SP4 & SP5 & SP6 & SP7 & SP8 \\
\hline $\mathrm{Pb}$ & $0.080 \pm 0.006$ & $0.080 \pm 0.008$ & $0.090 \pm 0.005$ & $0.070 \pm 0.005$ & $0.090 \pm 0.009$ & $0.090 \pm 0.007$ & $0.070 \pm 0.009$ & $0.070 \pm 0.007$ \\
\hline $\mathrm{Cr}$ & $0.240 \pm 0.007$ & $0.230 \pm 0.003$ & $0.260 \pm 0.006$ & $0.220 \pm 0.006$ & $0.230 \pm 0.012$ & $0.220 \pm 0.013$ & $0.310 \pm 0.010$ & $0.240 \pm 0.009$ \\
\hline $\mathrm{Cu}$ & $12.600 \pm 0.060$ & $12.400 \pm 0.100$ & $14.000 \pm 0.140$ & $11.000 \pm 0.140$ & $11.000 \pm 0.100$ & $12.000 \pm 0.160$ & $14.600 \pm 0.200$ & $15.400 \pm 0.220$ \\
\hline $\mathrm{Zn}$ & $1.940 \pm 0.010$ & $1.980 \pm 0.020$ & $2.320 \pm 0.024$ & $1.940 \pm 0.022$ & $2.160 \pm 0.018$ & $2.440 \pm 0.018$ & $2.660 \pm 0.020$ & $2.020 \pm 0.026$ \\
\hline $\mathrm{Ni}$ & $0.150 \pm 0.010$ & $0.150 \pm 0.005$ & $0.190 \pm 0.007$ & $0.160 \pm 0.009$ & $0.180 \pm 0.008$ & $0.240 \pm 0.010$ & $0.290 \pm 0.004$ & $0.160 \pm 0.007$ \\
\hline $\mathrm{Co}$ & $0.190 \pm 0.007$ & $0.180 \pm 0.008$ & $0.250 \pm 0.010$ & $0.180 \pm 0.011$ & $0.200 \pm 0.006$ & $0.260 \pm 0.008$ & $0.350 \pm 0.008$ & $0.220 \pm 0.009$ \\
\hline $\mathrm{Fe}$ & $6.500 \pm 0.125$ & $7.000 \pm 0.175$ & $9.750 \pm 0.100$ & $6.250 \pm 0.100$ & $12.750 \pm 0.200$ & $15.000 \pm 0.150$ & $10.250 \pm 0.175$ & $8.750 \pm 0.275$ \\
\hline $\mathrm{Mn}$ & $0.260 \pm 0.002$ & $0.270 \pm 0.003$ & $0.400 \pm 0.004$ & $0.180 \pm 0.004$ & $0.200 \pm 0.006$ & $0.310 \pm 0.002$ & $0.500 \pm 0.006$ & $0.520 \pm 0.006$ \\
\hline
\end{tabular}

Table 2. Elemental concentration of metals in the herbal concoction tea samples $(\mu \mathrm{g} / \mathrm{g})$.

Table 2. Continued.

\begin{tabular}{lllllll}
\hline Element $(\boldsymbol{\mu g} / \mathbf{g})$ & SP9 & SP10 & SP11 & Range & Mean \pm SD & CV $(\%)$ \\
\hline $\mathrm{Pb}$ & $0.090 \pm 0.011$ & $0.070 \pm 0.010$ & $0.080 \pm 0.011$ & $0.070-0.090$ & $0.080 \pm 0.008$ & 10 \\
$\mathrm{Cr}$ & $0.220 \pm 0.004$ & $0.220 \pm 0.009$ & $0.230 \pm 0.009$ & $0.220-0.310$ & $0.238 \pm 0.008$ & 3.361 \\
$\mathrm{Cu}$ & $16.200 \pm 0.280$ & $16.600 \pm 0.260$ & $17.200 \pm 0.220$ & $11.000-17.200$ & $13.909 \pm 0.170$ & 1.222 \\
$\mathrm{Zn}$ & $2.180 \pm 0.022$ & $2.140 \pm 0.026$ & $2.200 \pm 0.026$ & $1.940-2.660$ & $2.180 \pm 0.021$ & 0.963 \\
$\mathrm{Ni}$ & $0.150 \pm 0.009$ & $0.150 \pm 0.009$ & $0.250 \pm 0.006$ & $0.150-0.290$ & $0.188 \pm 0.007$ & 3.723 \\
$\mathrm{Co}$ & $0.210 \pm 0.011$ & $0.200 \pm 0.010$ & $0.320 \pm 0.007$ & $0.180-0.350$ & $0.232 \pm 0.008$ & 3.448 \\
$\mathrm{As}$ & $0.020 \pm 0.003$ & $0.030 \pm 0.004$ & $0.080 \pm 0.006$ & $0.020-0.080$ & $0.043 \pm 0.006$ & 13.953 \\
$\mathrm{Fe}$ & $23.250 \pm 0.250$ & $23.500 \pm 0.325$ & $21.500 \pm 0.275$ & $6.250-23.500$ & $13.136 \pm 0.195$ & 1.484 \\
$\mathrm{Mn}$ & $0.610 \pm 0.009$ & $0.610 \pm 0.009$ & $0.710 \pm 0.011$ & $0.180-0.710$ & $0.415 \pm 0.005$ & 0.043 \\
\hline
\end{tabular}

$\mathrm{SD}=$ standard deviation, $\mathrm{CV}=$ coefficient of variation

Analysis of variance

The single factor analysis of variance was carried out using Microsoft excel software package. The concentrations of the metals were used in the analysis. If $\mathrm{F}>\mathrm{F}$ critical, the 
null hypothesis is rejected. However, this is not the case as $0.22<1.94$ as shown in Table 3. Therefore, we accept the null hypothesis. The means of the eleven population are not all equal.

Table 3. Single factor analysis of variance.

\begin{tabular}{|c|c|c|c|c|c|c|}
\hline Groups & Count & Sum & Average & Variance & & \\
\hline SP1 & 9 & 22 & 2.44 & 18.89 & & \\
\hline SP2 & 9 & 22.33 & 2.48 & 18.93 & & \\
\hline SP3 & 9 & 27.32 & 3.03 & 26.73 & & \\
\hline SP4 & 9 & 20.06 & 2.22 & 14.90 & & \\
\hline SP5 & 9 & 26.85 & 2.98 & 26.03 & & \\
\hline SP7 & 9 & 29.06 & 3.22 & 29.00 & & \\
\hline SP8 & 9 & 27.40 & 3.04 & 29.34 & & \\
\hline SP9 & 9 & 42.93 & 4.77 & 75.43 & & \\
\hline SP10 & 9 & 43.52 & 4.83 & 77.80 & & \\
\hline SP11 & 9 & 42.57 & 4.73 & 70.28 & & \\
\hline Source of Variation & $S S$ & $d f$ & $M S$ & $F$ & P-value & $F$ crit \\
\hline Within Groups & 3370.16 & 88 & 38.29 & & & \\
\hline Total & 3453.80 & 98 & & & & \\
\hline
\end{tabular}

Correlation Matrix Analysis (CMA)

Correlation coefficient measures the strenght of the linear relationship between any two variables. In this study, the raw data was used in calculating the correlation coefficient using the Microsoft Excel computation software package.

Table 4 shows the CMA results of the analyzed metals in the herbal concoction tea samples; positive and strong significant correlations exist between $\mathrm{Zn} / \mathrm{Cr}, \mathrm{Ni} / \mathrm{Cr}, \mathrm{Co} / \mathrm{Cr}$, $\mathrm{Fe} / \mathrm{Cu}, \mathrm{Mn} / \mathrm{Cu}, \mathrm{Ni} / \mathrm{Zn}, \mathrm{Co} / \mathrm{Zn}, \mathrm{Co} / \mathrm{Ni}$ and $\mathrm{Mn} / \mathrm{Fe}$. Strong and significant positive correlations indicated chemical affinity, similar genetic origin and/or common background levels in the samples.

Table 4. Correlation Matrix of the Analyzed Metals in the Herbal concoction teas.

\begin{tabular}{|c|c|c|c|c|c|c|c|c|c|}
\hline & $\mathbf{P b}$ & $\mathrm{Cr}$ & $\mathrm{Cu}$ & Zn & $\mathbf{N i}$ & Co & As & $\mathbf{F e}$ & Mn \\
\hline $\mathrm{Pb}$ & 1 & & & & & & & & \\
\hline $\mathrm{Cr}$ & -0.25 & 1 & & & & & & & \\
\hline $\mathrm{Cu}$ & -0.21 & 0.09 & 1 & & & & & & \\
\hline $\mathrm{Zn}$ & 0.16 & 0.64 & 0.18 & 1 & & & & & \\
\hline $\mathrm{Ni}$ & $-1.4 \mathrm{E}-16$ & 0.61 & 0.14 & 0.84 & 1 & & & & \\
\hline Co & -0.05 & 0.66 & 0.42 & 0.82 & 0.94 & 1 & & & \\
\hline As & 0.23 & -0.16 & -0.16 & 0.06 & 0.38 & 0.29 & 1 & & \\
\hline $\mathrm{Fe}$ & 0.19 & -0.33 & 0.69 & 0.23 & 0.10 & 0.22 & -0.01 & 1 & \\
\hline $\mathrm{Mn}$ & -0.17 & 0.10 & 0.98 & 0.29 & 0.25 & 0.51 & -0.11 & 0.74 & 1 \\
\hline
\end{tabular}

$\mathrm{n}=11, \mathrm{r} \geq 0.60$ at $95 \%$ confidence interval

Pollution Index (PI) of the Heavy Metals in the Herbal concoction teas

The PI of the heavy metals in the herbal concoction tea samples was carried out to determine the extent of contamination/pollution associated with the samples. The PI of the analyzed metals was calculated using the concentration of the metals relative to the permissible limit set [19]. The PI values of the metals are presented in Table 2. The results of the PI show that the herbal concoction tea samples are clear of contamination with all the investigated metals except for $\mathrm{Cu}$ whose PI $>1$ (1.39).

Cluster Analysis (CA)

The hierarchical CA was used to determine the relationship among the various heavy metals using Euclidean distance as measure of similarity. This was performed using Statistical Package for Social Scientist (SPSS). Figure 1 is a dendrogram showing the results of $\mathrm{CA}$ of the analyzed metals in the samples.

Cluster analysis grouped the heavy metals into clusters on the basis of similarities within a group and dissimilarities between different groups. Parameters belonging to the same cluster are likely to have originated from a common source and/or similar chemical properties. The CA results indicates three groups namely: $\mathrm{A}$ ( $\mathrm{Pb}, \mathrm{As}, \mathrm{Cr}, \mathrm{Co}, \mathrm{Ni}, \mathrm{Mn}$ and $\mathrm{Zn}$ ), B $(\mathrm{Cu}$ and $\mathrm{Ni})$ and $\mathrm{C}(\mathrm{Fe}$ and $\mathrm{Cu})$. Group A showed the closest inter-element clustering, indicating similar chemical properties such as variable oxidation state etc; it may also be due to similar genetic origin or source. 


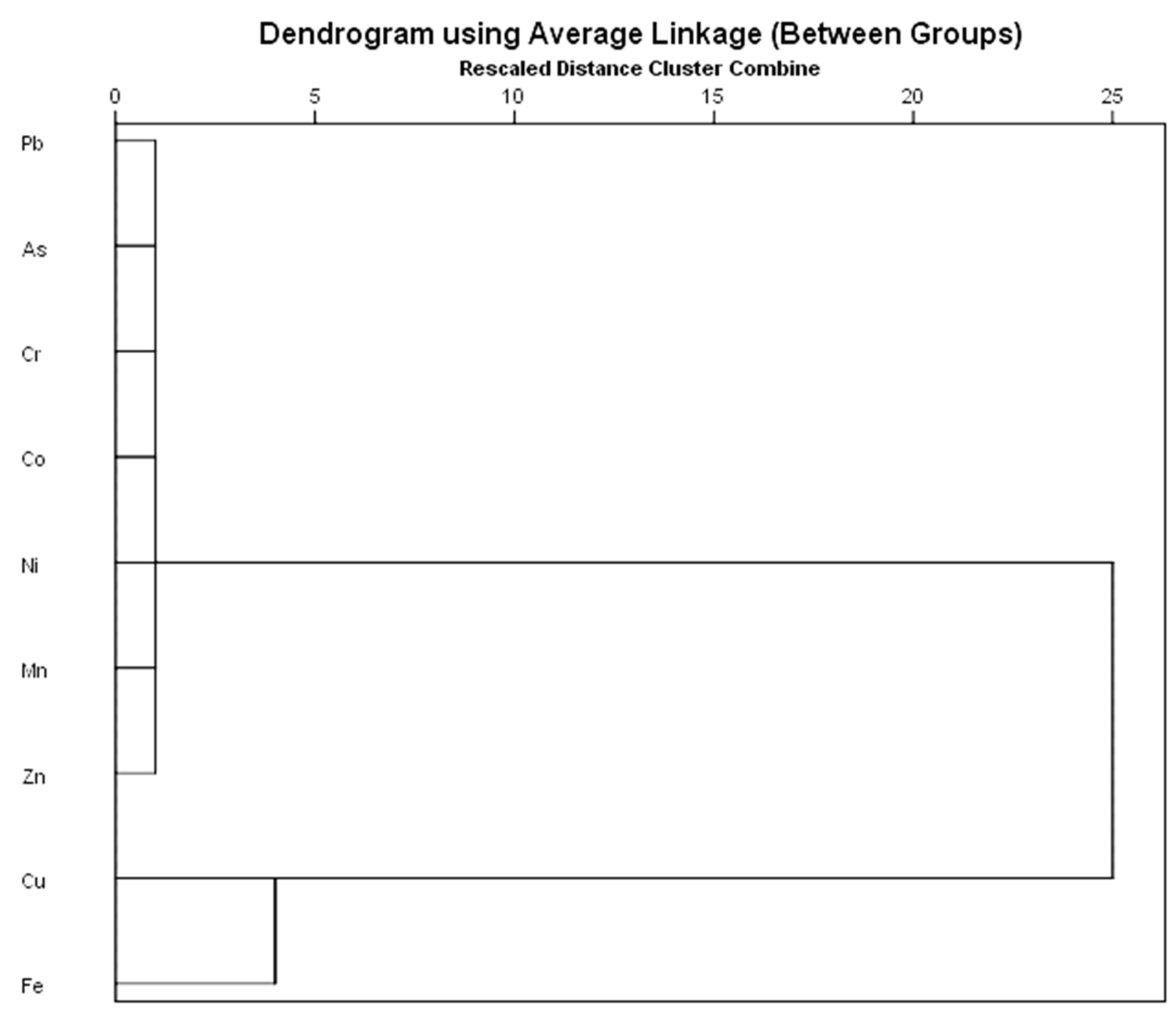

Figure 1. Dendrogram showing the hierarchical cluster analysis of the analyzed toxic metals in the herbal concoction teas.

Comparison of the total elemental concentrations with similar studies

The comparison of the concentrations of the analyzed metals in this study with similar studies is presented in Table 5. The concentrations of $\mathrm{Pb}, \mathrm{Cu}$ and $\mathrm{Cr}$ reported in this study was higher than that reported in Heavy Metal Analysis from Traditionally used Herb Ceropegia juncea (Roxb.) [20]. While $\mathrm{Pb}$ and $\mathrm{Cr}$ were lower than those reported [8] in Phytochemical properties and heavy metal contents of commonly consumed alcoholic beverages flavoured with herbal extract in Nigeria. The level of Co obtained in this study is consistent with the result reported [8] while $\mathrm{Zn}$ and $\mathrm{Fe}$ concentrations were higher. Zinc and $\mathrm{Mn}$ in this study were higher than the result reported [20] while As was lower. These variations could be attributed to the differences in the types of herbal plant extracts investigated and their ability to retain metals.

Table 5. Comparison of the total elemental concentration in this study with similar studies.

\begin{tabular}{llll}
\hline Element $(\boldsymbol{\mu g} / \mathbf{g})$ & This study & {$[\mathbf{2 0}]$} & {$[\mathbf{8}]$} \\
\hline $\mathrm{Pb}$ & 0.080 & 0.002 & 4.70 \\
$\mathrm{Cr}$ & 0.238 & 0.036 & 0.35 \\
$\mathrm{Cu}$ & 13.909 & 1.637 & $\mathrm{NDT}$ \\
$\mathrm{Zn}$ & 2.180 & 0.247 & 0.40 \\
$\mathrm{Co}$ & 0.232 & $\mathrm{NDT}$ & 0.23 \\
\hline
\end{tabular}

\begin{tabular}{llll}
\hline Element $(\boldsymbol{\mu} \mathbf{g} / \mathbf{g})$ & This study & {$[\mathbf{2 0}]$} & {$[\mathbf{8}]$} \\
\hline As & 0.043 & 0.60 & NDT \\
$\mathrm{Fe}$ & 13.136 & NDT & 4.22 \\
$\mathrm{Mn}$ & 0.415 & 0.017 & NDT \\
\hline
\end{tabular}

$\mathrm{NDT}=$ not determined

Human Health Risk Assessment

Estimation of Estimated Daily Intake (EDI) and Target Hazard Quotient (THQ)

The oral reference dose based on the recommendations of United States Environmental Protection Agency (USEPA) is presented in Table 6. The estimated daily intake for $\mathrm{Pb}$, $\mathrm{Cr}, \mathrm{Cu}, \mathrm{Zn}, \mathrm{Ni}, \mathrm{Co}, \mathrm{As}, \mathrm{Fe}$ and $\mathrm{Mn}$ are 9.01E-05, 2.68E-05, $0.00156,0.00024,2.11 \mathrm{E}-05,2.61 \mathrm{E}-05,4.84 \mathrm{E}-06,0.00148$ and 4.67E-05 respectively. These results showed that the EDI for the investigated metals were lower than the RfD (oral reference dose). These indicated that the intake of the herbal concoctions might not have an adverse effect on the health of the populace consuming it. The target hazard quotient (THQ) is according to the order: $\mathrm{Co}>\mathrm{Cu}>\mathrm{As}>$ $\mathrm{Cr}>\mathrm{Fe}>\mathrm{Pb}>\mathrm{Ni}>\mathrm{Zn}>\mathrm{Mn}$. The THQ of each metal from the consumption of the teas was generally less than 1 . This suggests that the consumption of the herbal concoctions would not cause significant health risks from the intake of individual metals. 
Table 6. Estimated Target Hazard Quotients (THQ), Cancer Risk (CR) and Relative Risks (RR) for analyzed metals from consumption of herbal concoction teas.

\begin{tabular}{lllllll}
\hline Heavy metal $(\boldsymbol{\mu g} / \mathbf{g})$ & EDI & RfD & THQ & CSF & CR & RR (\%) \\
\hline $\mathrm{Pb}$ & $9.01761 \mathrm{E}-06$ & 0.004 & 0.00225 & $8.5 \times 10^{-3}$ & $7.66497 \mathrm{E}-10$ & 1.40 \\
$\mathrm{Cr}$ & $2.68274 \mathrm{E}-05$ & 0.003 & 0.00894 & - & - & 5.55 \\
$\mathrm{Cu}$ & 0.00156 & 0.04 & 0.03919 & - & - & 24.36 \\
$\mathrm{Zn}$ & 0.00024 & 0.3 & 0.00081 & - & - & 0.50 \\
$\mathrm{Ni}$ & $2.11914 \mathrm{E}-05$ & 0.02 & 0.00106 & 1.7 & $-3.60254 \mathrm{E}-07$ & 0.65 \\
$\mathrm{Co}$ & $2.61511 \mathrm{E}-05$ & 0.0003 & 0.08717 & - & - & 54.18 \\
$\mathrm{As}$ & $4.84697 \mathrm{E}-06$ & 0.0003 & 0.01615 & - & - & 10.04 \\
$\mathrm{Fe}$ & 0.00148 & 0.3 & 0.00493 & - & - & 3.06 \\
$\mathrm{Mn}$ & $4.67789 \mathrm{E}-05$ & 0.14 & 0.00033 & - & - & 0.20 \\
$\mathrm{TTHQ}$ & & & 0.16086 & - & & \\
\hline
\end{tabular}

$\mathrm{EDI}=$ estimated daily intake, $\mathrm{RfD}=$ oral reference dose, $\mathrm{THQ}=$ target hazard quotient, $\mathrm{TTHQ}=$ total target hazard quotient, $\mathrm{CSF}=$ cancer slope factor, $\mathrm{CR}=$ cancer risk, $\mathrm{RR}=$ relative risk

Estimation of the Cancer Risk (CR) for Lead and Nickel; and Relative Risk

The estimated factors of the cancer risk for $\mathrm{Pb}$ and $\mathrm{Ni}$ and relative risk are presented in Table 6. Based on the result of this study, the $\mathrm{CR}$ factor for $\mathrm{Pb}$ and $\mathrm{Ni}$ over a lifetime of exposure through contaminated herbal concoction tea consumption are $7.66497 \times 10^{-10}$ and $3.60254 \times 10^{-8}$ respectively. The tolerable value of lifetime carcinogenic risk set by USEPA is $10^{-5}$. The cancer risk factors of $\mathrm{Pb}$ and $\mathrm{Ni}$ obtained in this study are lower than the set tolerable limit, indicating that the consumption of the herbal concoction teas might not pose carcinogenic risk for $\mathrm{Pb}$ and $\mathrm{Ni}$.

The non-carcinogenic relative risk (RR) values for the consumption of contaminated herbal concoction teas for all the metals is of the order: $\mathrm{Co}>\mathrm{Cu}>\mathrm{As}>\mathrm{Cr}>\mathrm{Fe}>\mathrm{Pb}>$ $\mathrm{Ni}>\mathrm{Zn}>\mathrm{Mn}$. The contribution of Co is $54.18 \%$, while that of $\mathrm{Mn}$ is $0.20 \%$. The highest concern of herbal tea consumption is related to Co.

\section{Conclusion and Recommendation}

The study investigated some selected potential toxic metals and their associated health risks to humans. The pollution index values of the metals showed that the metals have values lower than 1 , only $\mathrm{Cu}$ showed a PI $>1$ which indicated a level of contamination for the samples. Correlation matrix and cluster analysis indicated significant relationship between the analyzed metals which suggested similar sources and/or genetic origin for the metals. The estimated daily intake was less than the oral reference dose for the consumers. The target hazard quotient was also less than 1 . The cancer risk was also less than the set tolerable limit. The health risk assessment showed that the concentrations of the investigated potential toxic metals will not pose threat to the health of the consumers. However, based on the results obtained for the relative risk, among the considered metals, the main risk for human health can be related to the amount of Co. Due to the possible accumulation of metals in plants, it is recommended that the herbal concoction teas should be consumed moderately.

\section{References}

[1] Fabricant, D. S. and Farnsworth, N. R. 2001. "The value of plants used in traditional medicine for drug discovery," Environmental Health Perspectives, vol. 109, no. 1, pp. 69-75.

[2] Sahoo, N., Manchikanti, P. and Dey, S. 2010. "Herbal drugs: standards and regulation," Fitoterapia, vol. 81, no. 6, pp. 462-471.

[3] World Health Organization (WHO), 2002. Traditional Medicine Strategy (2002-2005), World Health Organization, Geneva, Switzerland.

[4] Duffus J. H. 2002. "Heavy metals" a meaningless term? (IUPAC Technical Report). Pure and applied chemistry. 74 (5): 793-807.

[5] Kim, M. K., Kim, W. L., Jung, G. B., Yun, S. G. 2001. Safety assessment of heavy metals in agricultural products of Korea. Korean Journal of Environmental Agriculture. 20: 169-332 174.

[6] Duruibe, J. O., Ogwuegbu, M. O. C. and Egwurugwu, J. N. 2007. Heavy metal pollution and human biotoxic effects. International Journal of Physical Sciences. 2 (5), 112-118.

[7] Ernst, E. 2002. "Toxic heavy metals and undeclared drugs in Asian herbal medicines," Trends in Pharmacological Sciences, vol. 23, no. 3, pp. 136-139.

[8] Okareh, O., Oyelakin, T., and Ariyo, O. 2018. Phytochemical Properties and Heavy Metal Contents of Commonly Consumed Alcoholic Beverages Flavoured with Herbal Extract in Nigeria. Beverages. 4 (3), 60. doi: $10.3390 /$ beverages 4030060 .

[9] Ogner, G., Opem, M., Remedios, G. and Sjorlie, B. 1991. The Chemical analysis program of the Norwegian Forest Research Institute, As, Norway, 224-330.

[10] Oyewole, F. G. and Adebiyi, F. M. 2017. Total and speciation analyses of heavy metals in the sand fraction of Nigerian oil sands for human and ecological risk assessment. Human and Ecological Risk Assessment: An International Journal. 23 (8): 2046-2068.

[11] USEPA 1989. Risk assessment guidance for superfund, Human Health Evaluation Manual Part A, Interim Final vol. I, United States Environmental Protection Agency, Washington DC. 
[12] USEPA (United States Environmental Protection Agency) 2015. Regional Screening Level (RSL) Summary Table, November 2015.

[13] USEPA, 2000. Agency, U. S. E. P. Supplementary guidance for conducting health risk assessment of chemical mixtures.

[14] Chien, L. C., Hung, T. C., Choang, K. Y., Yeh, C. Y., Meng, P. J., Shieh, M. J., and Han, B. C. 2002. Daily intake of TBT, Cu, $\mathrm{Zn}, \mathrm{Cd}$ and As for fishermen in Taiwan. Science of the Total Environment. 285, 177-185.

[15] Peng, Q., Nunes, L. M., Greenfield, B. K., Dang, F., and Zhong, H. 2016. Are Chinese consumers at risk due to exposure to metals in crayfish? A bioaccessibility-adjusted probabilistic risk assessment. Environment International. 88, 261-268.

[16] Shaheen, N., Irfan, N. M., Khan, I. N., Islam, S., Islam, M. S., and Ahmed, M. K. 2016. Presence of heavy metals in fruits and vegetables: health risk implications in Bangladesh. Chemosphere. 152, 431-438.
[17] Saha, N., Mollah, M., Alam, M., and Rahman, M. S. 2016. Seasonal investigation of heavy metals in marine fishes captured from the bay of Bengal and the implications for human health risk assessment. Food Control. 70, 110-118.

[18] Yu, Y., Wang, X., Yang, D., Lei, B., Zhang, X., and Zhang, X. 2014. Evaluation of human health risks posed by carcinogenic and non-carcinogenic multiple contaminants associated with consumption of fish from Taihu Lake, China. Food and Chemical Toxicology. 69, 86-93.

[19] World Health Organization, WHO. 2006. Guidelines for Assessing Quality of Herbal Medicines with Reference to Contaminants and Residues, World Health Organization, Geneva, Switzerland.

[20] Karayil Sudha, Bhavani and Vivek Ch. 2014. Heavy metal analysis from traditionally used herb Ceropegia juncea (Roxb.). IOSR Journal of Pharmacy. 4 (12): 07-11. 